University of Arkansas, Fayetteville

ScholarWorks@UARK

Education Reform Faculty and Graduate

Students Publications

Education Reform

2-23-2019

\title{
Does Art Make You Smart? A Longitudinal Experiment of the Effects of Multiple Arts- Focused Field Trips
}

\author{
Heidi Holmes Erickson \\ University of Arkansas, Fayetteville \\ Jay Greene \\ University of Arkansas, Fayetteville \\ Angela Watson \\ University of Arkansas, Fayetteville \\ Molly I. Beck \\ University of Arkansas, Fayetteville
}

Follow this and additional works at: https://scholarworks.uark.edu/edrepub

Part of the Educational Assessment, Evaluation, and Research Commons, Educational Leadership Commons, and the Other Educational Administration and Supervision Commons

\section{Citation}

Erickson, H. H., Greene, J., Watson, A., \& Beck, M. I. (2019). Does Art Make You Smart? A Longitudinal Experiment of the Effects of Multiple Arts- Focused Field Trips. Education Reform Faculty and Graduate Students Publications. Retrieved from https://scholarworks.uark.edu/edrepub/88

This Article is brought to you for free and open access by the Education Reform at ScholarWorks@UARK. It has been accepted for inclusion in Education Reform Faculty and Graduate Students Publications by an authorized administrator of ScholarWorks@UARK. For more information, please contact scholar@uark.edu. 


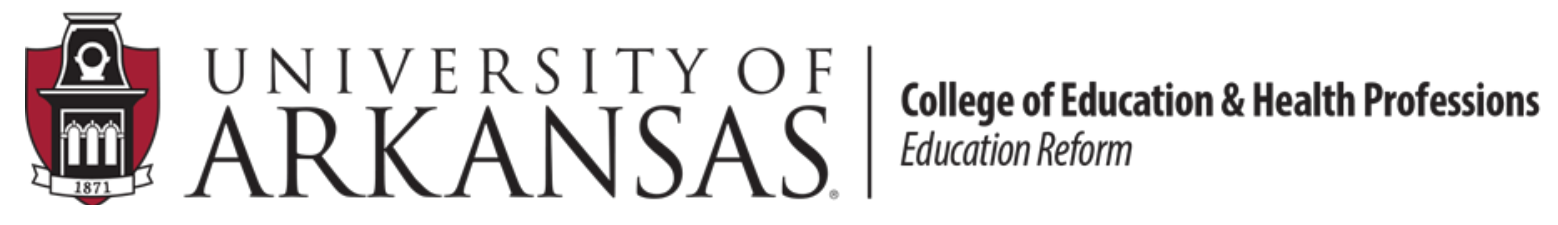

\title{
WORKING PAPER SERIES
}

\section{Does Art Make You Smart? A Longitudinal Experiment of the Effects of Multiple Arts- Focused Field Trips}

\author{
Heidi Holmes Erickson* \\ University of Arkansas \\ hh018@email.uark.edu \\ Jay P. Greene \\ University of Arkansas \\ Angela R. Watson \\ University of Arkansas \\ Molly I. Beck \\ University of Arkansas
}

Last Revised February 2019

EDRE Working Paper 2019-05

*corresponding author

The University of Arkansas, Department of Education Reform (EDRE) working paper series is intended to widely disseminate and make easily accessible the results of EDRE faculty and students' latest findings. The Working Papers in this series have not undergone peer review or been edited by the University of Arkansas. The working papers are widely available, to encourage discussion and input from the research community before publication in a formal, peer reviewed journal. Unless otherwise indicated, working papers can be cited without permission of the author so long as the source is clearly referred to as an EDRE working paper. 
The opinions expressed in this paper are those of the authors and do not represent the views of the National Endowment for the Arts Office of Research \& Analysis or the National Endowment for the Arts (NEA). The NEA does not guarantee the accuracy or completeness of the information included in this material and is not responsible for any consequences of its use. The University of Arkansas NEA Research Lab is supported in part by a grant award from the Research Labs program at the National Endowment for the Arts (Grant \#: 17-3800-7016). 


\begin{abstract}
This paper presents second year results from the first ever multi-visit, longitudinal experiment on the benefits from arts-focused field trips. Students in fourth and fifth grades in ten elementary schools in a large urban school district were randomly assigned to receive three arts-related field trips throughout the school year, including an art museum, a live theater production, and a symphony performance or to serve as a control. We find that treatment students exhibit higher levels of school engagement as measured by students' behavioral infractions and self-reported engagement. We also find that treatment students perform significantly better on their end of year standardized tests, up to $16 \%$ of a standard deviation increase. These effects are persistent even one year following treatment. However, the effects appear to be stronger for the first cohort of students in our sample.
\end{abstract}

Keywords: art education, field trips, school engagement, test scores 


\section{Introduction}

In this paper we estimate the causal effects of culturally enriching field trips on students' academic performance and school engagement. Such field trips are a long-standing tradition in schools. There are many potential benefits for students from attending culturally enriching field trips. Field trips to cultural institutions, particularly arts institutions, expose students to new ideas, places, and cultures while providing opportunities to deepen learning outside of the traditional classroom. Arts institutions provide meaningful opportunities not only to see, hear, and discuss works of arts, but expose students to a world beyond what they know. Many students, especially in low-income areas, experience little beyond their homes, neighborhoods, and schools. Field trips can vastly expand what children experience as part of their schooling. Field trips to cultural institutions such as art museums and theaters continue mostly due to the wisdom of educators and historical tradition. However, in recent decades, institutions such as arts venues, science museums, and zoos have noticed a decline in field trip attendance (Ellerson \& McCord, 2009; Greene, Kisida, \& Bowen, 2014). Teachers and students also reported a decline in school sponsored field trips (Government Accountability Office, 2009; Keiper et al., 2009).

Some evidence suggests that schools are reducing the number of field trips due to increased pressure from high-stakes accountability (Gadsden, 2008; Government Accountability, 2009; Rabkin \& Hedberg, 2011). Under test-based accountability systems schools are under pressure to reconsider the costs and benefits of traditional educational field trips as they focus on increasing math and reading test scores (Gadsden, 2008; Rabkin \& Hedberg, 2011; Student Youth \& Travel Association, 2016). Responding to these pressures, schools allocate additional time to instruction, specifically in math and reading, and test preparation while cutting back on non-tested subjects and other activities such as field trips. Notably, academically low-performing 
schools that serve students from high-poverty areas are more likely to report a decline in schoolsponsored field trips, including arts-focused trips (Government Accountability Office, 2009; Keiper et al., 2009). These schools also face the greatest accountability pressures. A decline in field trips in high-poverty areas is especially concerning as field trips can provide equitable access to cultural institutions for students across various economic and racial groups.

Unfortunately, there is little systematic evidence on the value of cultural field trips for students. However, foregoing field trips could have unintended consequences for students as time in school is allocated to other academic activities in hopes of increasing student test scores. We seek to increase the literature on the impacts of field trips with the goal of better understanding the benefits for students and what might be lost if schools continue to decrease such activities. We expand the literature on the educational benefits of field trips by conducting, to our knowledge, the first-ever multi-visit, longitudinal experiment to estimate these effects. We randomly assign fourth and fifth grade students in ten elementary schools in a large urban school district to receive multiple arts-related field trips throughout the school year or to serve as a control group. This paper presents the results from the second year of the study. Our findings show significant educational benefits for students who attend arts-related field trips. We find that treatment students exhibit higher levels of school engagement. Surprisingly and contrary to our hypothesis, we find that treatment students also perform significantly better on their end-of-year standardized tests, and that this effect is persistent one year after treatment. These effects appear to be stronger for the first cohort of students in our sample.

The paper proceeds as follows. First, we discuss the previous literature on the impact of field trips and arts exposure for students. Second, we present our research questions and describe 
the study design. We then present our results and conclude with discussing policy implications and future research.

\section{Previous Literature}

Despite the educational tradition of fieldtrips, there is limited rigorous research evaluating the effects students experience from such activities. We draw on the literature evaluating the benefits of arts education as well as research on specific field trips. We group the literature based on research design pulling from both observational and experimental designs.

\section{Observational Studies}

There are a handful of observational studies focusing on the value of the arts for students' academic and social development. Longitudinal studies find positive correlations between arts exposure and academic outcomes (Ruppert, 2006; Lacoe, Painter, \& Williams, 2016). Jægar and Møllegarrd (2017), comparing identical twins, find that children who frequent museums, theaters, and musical performances when they are younger also perform better in school when they are teenagers. Notably, a recent meta-analysis on the effects of student achievement from arts integration programs finds a four-percentage point increase in achievement (Ludwig, Boyle, \& Lindsay, 2017). While a four-percentage point increase reflects significant academic gains, the authors warn against causal interpretation as none of the studies in the meta-analysis were able to establish a causal connection between arts activities and academic performance. Further, Lacoe, Painter, \& Williams (2016) evaluate an arts integration program and find evidence that the dosage of exposure is important; students who receive longer and more intensive dosages experience larger academic gains and fewer school suspensions. However, they also find diminishing effects once treatment ceases. 
Other research has found social and emotional benefits from exposure to the arts. A recent study looking at single-visit art museum field trips finds that students experience increases in critical thinking, creative thinking, and human connection (Randi Korn \& Associates, 2018). Human connection is defined as an awareness or sense of connection to others and the self and is similar to the construct of social perspective taking (Gehlbach, Brinkworth, \& Wang, 2012; Greene et al., 2018). In addition to a single art museum visit, the study adds a second treatment condition of a near identical arts program that takes place in a classroom instead of in the museum. The authors find that the in-gallery experience appears to be more impactful than simply seeing and discussing identical art content at school (Randi Korn \& Associates, 2018).

\section{Experimental Studies}

Fortunately, there is a growing, yet still limited, body of literature on the causal effects for students from arts integration and specifically, arts-related field trips. A study of a districtwide arts enrichment program where, due to budget constraints, schools were randomly chosen to participate, shows positive outcomes on students' compassion for others, school engagement, as well as increased standardized test scores (Bowen \& Kisida, 2019). Greene, Kisida, and Bowen (2014) experimentally evaluate the effects of a single visit to an art museum on student outcomes and find that students who tour an art museum demonstrate a host of significant benefits when measured nearly two months after the visit occurs. Treatment students are more likely to report a greater desire to consume art in the future and actually visit the same art museum on their own following the field trip (Kisida, Greene, \& Bowen, 2014). In addition, there is evidence that treatment students demonstrate increased levels of critical thinking skills, as well as increased tolerance, content knowledge, and historical empathy (Bowen, Greene, \& Kisida, 2014; Greene, Kisida, \& Bowen, 2014). Further, these benefits appear stronger for 
students from low socioeconomic backgrounds.

In a similar experimental study evaluating the effects of attending field trips to see live theater performances, students demonstrate higher levels of tolerance, social perspective taking, and evidence of increasing desire to consume theater in the future (Greene, et al., 2015; Greene et al., 2018). Particularly interesting, Greene et al. (2018) adds a second treatment condition wherein some students receive a field trip to a live theater performance, some receive a field trip to see a movie of the same play, and the control group remains at school and receives neither the play nor the movie treatment. Students who view the live theater performance demonstrate higher levels of tolerance, social perspective taking, and content knowledge compared to the students who viewed a movie of the same play.

Our current study adds to the existing literature on the benefits of culturally enriching field trips in four ways. First, we use an experimental design that allows us to capture the causal effects on students from attending field trips. Second, where most of the previous literature focuses on the effects from attending one field trip, treatment students in this study attend three different arts-related field trips: an art museum, live theater, and the symphony. Third, this study takes place in a large urban city, and the participating schools consist primarily of students of color who are from economically disadvantaged backgrounds. Much of the existing research was conducted in suburban and rural areas. Fourth, this study is the first longitudinal experiment where we collect both survey and administrative data for students in our sample.

\section{Research Question and Hypotheses}

This paper examines whether attending multiple arts-focused field trips throughout the school year improves students' engagement in school and affects their academic performance. 
We measure the effect of receiving three field trips in one year, six field trips over two years, and the effect one year following treatment. We set the following hypotheses:

H1: We expect that treatment students will demonstrate higher levels of school engagement.

H1a: We expect treatment students to report higher levels of school engagement through self-reported measures on surveys than their control counterparts.

H1b: We also expect treatment students to have fewer behavioral infractions throughout the school year than their control counterparts.

$\mathrm{H} 2$ : We expect to find no statistically significant treatment effect on students' end of year standardized test scores.

We hypothesize that treatment students will demonstrate higher levels of school engagement by spending time away from traditional instruction and being exposed to new ideas and art forms with which they are unfamiliar. Exposing students to new ideas sparks their creativity and desire to learn. When students are excited about a certain subject or idea, they are naturally more engaged in school. It is also possible, that simply providing a break from traditional instruction motivates and refreshes students so that they enjoy school more. There is not a comprehensive measure of school engagement; we use a self-reported and behavioral measure to capture students' engagement. First, we use students' self-reports on how boring they believe school is. Second, we use the number of infractions a student receives in a year. Students who are engaged in school are less likely to act out. Using both self-reported and behavioral measures provides a good proxy for students' engagement in school.

While field trips can expose students to arts and provide a unique learning environment, it is unlikely that three arts-related trips will significantly affect students' academic performance 
on math or reading exams. Three days away from traditional instruction is unlikely to harm student achievement nor provide enough content to improve test scores. While some previous studies have found positive effects on students' academic performance from arts exposure, these studies have evaluated more intensive arts integrations programs. We are evaluating a less intensive program of only arts-related field trips. As such, we expect to find no significant difference between treatment and control students' test scores.

\section{Study Design}

In partnership with The Woodruff Arts Center in Atlanta, Georgia and a large urban school district, we randomly assign fourth and fifth grade classes within ten elementary schools to receive a field trip to each of the three Woodruff arts partners, the Alliance Theatre, the Atlanta Symphony Orchestra, and the High Museum of Art, or to serve as a control group. The Woodruff Arts Center is a world-class center that offers some of the nation's leading exhibits and facilities. The three high-quality field trips, all part of the otherwise existing educational programming at each venue, are carefully designed for maximum impact and cultural relevancy. The hour-long Alliance Theatre performance is designed for children and families and performed by a professional cast and is of the highest artistic quality. A trained volunteer docent leads the hour-long High Museum of Art's program featuring several works of art followed by an hourlong hands-on studio experience led by a teaching artist. Finally, the Atlanta Symphony Orchestra fills their 1,700-seat facility for an hour-long concert with a full symphony performing music carefully selected for younger audiences and accented with large-screen video descriptions and images.

In the first year of the study there were four participating schools, and in year two six additional schools were included for a total of ten schools. Randomization occurred within schools between the fourth and fifth grade. We ensured that we had equal numbers of fourth and 
fifth grades that were assigned to treatment and control. For example, in the first year of the study with four participating schools, two schools had fourth grade receive treatment and fifth grade serve as a control; while the other two schools had fifth grade receive treatment and fourth grade serve as a control. Treatment students who were in fourth grade in the first year received an additional year of treatment when they were in fifth grade the following year. Table 1 shows treatment assignment in year two for each school and grade. In year two, we are able to estimate the effect of three field trips in one year, six field trips in two years, and the effect of three field trips a year following the treatment.

\section{TABLE 1}

Ideally, we would prefer to randomize individual students to the treatment or control group; however, it is logistically difficult to take a mix of fourth and fifth grade students from different classes and schools on three field trips throughout the year. We wanted to minimize the administrative burden on the schools and create minimal disruption to their normal schedules. It was easier on schools and more efficient for entire grades within a school to attend the field trips. We believe that our design remains a rigorous experiment because participating students are very similar to each other prior to randomization, therefore increasing the probability of having similar treatment and control groups. First, all the schools are in the same large urban school district. The ten elementary schools are all near each other and feed into two neighboring middle schools. Second, the ten schools all serve very similar student populations. Students live in a large, urban area and are primarily students of color and the majority qualify for free or reducedprice lunch (FRL). Third, fourth and fifth grade students in the same schools are relatively similar to each other. The primary reason students are either in fourth or fifth grade is their birthday. We also believe that arts-related field trips are unlikely to affect fourth grade students 
in a significantly different way than fifth grade students in the same school. If, by chance, there are significant differences between fourth and fifth graders, our design accounts for the differences by ensuring a balance of fourth and fifth grades across the treatment and control groups.

Following randomization, our research team surveyed all students at the beginning of the school year. The treatment group then attended the three field trips throughout the course of the school year. It is important to note that the treatment consisted of the three field trips and one day of professional development for teachers in treatment grades conducted by The Woodruff Arts Center. Any supplementary activities either before or following any of the field trips were done at the discretion of the teacher or school. The control group received business as usual which could have been up to one field trip to various locations in Atlanta throughout the school year. Our team then administered post surveys near the end of the school year following the end-ofgrade exams. We also received administrative data from the school district for all students in the year prior to them entering the study and each year following.

\section{Sample and Data}

Our sample consists of just under 1,400 students who are 10.5 years old on average. Over $90 \%$ of the students in our sample identify as black or African American. We do not report the percent of students who qualify for FRL because the majority of schools in our sample record all students as qualifying for FRL. Table 2 includes demographic and pre-treatment measures for treatment and control groups separately.

Our treatment and control groups are statistically similar to each other at baseline on key measures such as demographics, special education status, test scores, discipline measures, and school attendance (Table 2, Column 3). Most of these measures come from administrative data 
provided by the school district. There are some statistically significant differences between the treatment and control groups on pre-treatment survey measures. Treatment students report greater desires to consume art in the future (Table 2, Column 3). However, we believe these differences are due to teachers priming treatment students prior to our pre-treatment surveys and are not due to underlying differences between the two groups. Teachers were aware of their class' treatment assignment prior to surveying due to scheduling constraints. Many teachers told the students before beginning the survey that they were going to attend various field trips throughout the year and discussed the importance of museums and theaters prior to survey administration. We believe these differences reflect some effect of the treatment if students exhibit interest in the arts when they simply anticipate attending the given institutions. We controlled for baseline desire to consume art in our analysis and it does not affect our outcomes of interest in any significant ways.

\section{TABLE 2}

\section{Consent and Attrition}

We received consent to participate in the study from $78 \%$ of all enrolled fourth and fifth grade students in the ten elementary schools. Of the enrolled students, we did not receive a spring survey from $39.6 \%$ of students. There was a $6.8 \%$ differential attrition rate between the treatment and control groups with more students leaving the control group. We received school district administrative data from nearly all students who consented to the study. However, we received more consent forms from the treatment than the control group. Therefore, when using administrative data, we have a $15.7 \%$ differential attrition rate between the treatment and control groups. 
When using only survey data, the overall and differential attrition rates fall within the What Works Clearinghouse tolerable threat of bias under optimistic assumptions (What Works Clearinghouse). We believe the optimistic assumptions are appropriate for this study because it is unlikely that treatment status affects the attrition of a student from our sample. Students in our sample are a highly mobile population and movement within the year is fairly common as seen in the overall attrition rate.

When district administrative data is included, however, we have a higher threat of bias under the What Works Clearinghouse guidelines. The administrative data has significant benefits, despite the high differential attrition between the treatment and control groups. Administrative data provides data on students who leave their original school but stay within the district. It also provides a rich set of control and outcome variables of interest. Unfortunately, issues with consent and attrition are common in field work. As a robustness check, we ran our analysis with administrative data limiting it to students who have spring surveys. All effects remain in the same direction and are typically stronger in magnitude and statistically significant at higher confidence levels when just using students with survey and administrative data. In this paper, we present the analysis that includes all students from whom we received administrative data.

\section{Outcome Measures}

In this paper we focus on the effects field trips have on students' academic performance and school engagement. To measure academic performance, we use a composite math and English language arts (ELA) score on the Georgia Milestones end-of-grade exams. The Georgia Milestones are given to all public school students in the state starting in third grade and the exam scores are used in Georgia's accountability system. In our analysis, we include baseline test 
scores which are from the school year prior to treatment ${ }^{1}$. All test scores are standardized within grade level and presented in standard deviation effect sizes.

To measure school engagement, we use the number of infractions a student receives during the school year as well as the student's self-reported responses of how boring school is. In the district administrative data, we are able to see every time a student is written up for a behavioral infraction. We use the number of infractions during the treatment year as our outcome variable and control for the number of infractions in the prior year. For student self-reports, students indicate how much they agree with the statement "School is boring" on a five-point scale from disagree a lot to agree a lot. We control for pre-treatment responses to the same statement. All pre- and post-treatment responses are standardized. We recognize that these two measures do not capture all forms of student engagement, but believe they capture important elements of school engagement.

Analyses

Due to the randomized field trial design, which generates similar treatment and control groups, we use a straightforward analytic approach to estimate the causal effect of attending artsrelated field trips on students' academic performance and school engagement. Our technique estimates mean differences between the treatment and control groups using the following equation for outcome $Y$ for student $\mathrm{i}$ in school s:

$$
\begin{gathered}
Y_{i s}=\beta_{0}+\beta_{1} \text { Treat }_{i s}+\beta_{2} \text { 2Treat }_{i s}+\beta_{3} \text { PTreat }_{i s}+\beta_{4} \text { Baseline }_{i s}+X_{i} \beta_{5}+\theta_{s}+ \\
\alpha_{i}+\varepsilon_{i s}
\end{gathered}
$$

\footnotetext{
${ }^{1}$ For our baseline test score measure, we use a combined standardized score of all Georgia Milestone exams a student took in the year prior to a treatment. All students took the math and ELA milestone while some students also took the science and social studies exams.
} 
Where 1Treat is a binary variable equal to 1 if a student receives one dosage of treatment, 2Treat is equal to 1 if a student receives a second dosage of treatment, and PTreat is equal to 1 if a student receives treatment in the prior year. In order to increase the precision of our estimates, we include baseline measures of the outcome, Baseline, and a vector of student characteristics, $X$, which includes binary variables for a student's gender and if the student is in sixth grade. Because randomization occurred within schools, $\theta$ is a fixed effect for each school, which effectively compares treatment and control students within the same school instead of across schools. We also include student random effects, $\alpha$, to account for correlation between a student's error over the two years. It is important to note that we have an unbalanced panel data set where cohort one students appear in year one and year two, and cohort two students only appear in year two. We believe random effects are appropriate because we are correcting for student errors correlated over time and not trying to account for potential endogeneity where fixed effects would be more appropriate. Finally, $\varepsilon$ is the stochastic error term clustered at the teacher level to account for spatial correction from students in the same classroom.

\section{Results}

\section{Student Academic Performance}

As reflected in Table 3, receiving the opportunity to attend three field trips has a marginally statistically significant effect at the $90 \%$ confidence level on students' math and ELA test scores the year following treatment. Receiving treatment in a prior year leads to a 0.12 standard deviation increase in the following year test scores. However, the effect on test scores varies when looking at cohorts one and two separately. Cohort one students who receive the first dosage of treatment experience a statistically significant 0.15 standard deviation increase in test scores compared to their control counterparts. This effect is significant at the $95 \%$ confidence 
level. The effect persists a year after treatment, where treatment students score 0.13 standard deviations higher than control students. The effect slightly increases with a second dosage of treatment, where treatment students score 0.17 standard deviations higher than control students; however, it is only statistically significant at the $90 \%$ confidence level. These effects do not appear for cohort two students.

\section{TABLE 3}

\section{Student School Engagement}

As reflected in Table 4, receiving the opportunity to attend three arts-related field trips significantly increases student engagement a year following treatment when measured by the number of disciplinary infractions and self-reports. Treatment students have 0.6 fewer infractions than their control counterparts in a year after treatment. This effect is significant at the $95 \%$ confidence level. They also reported that school was less boring by 0.33 standard deviations; however, this effect is only significant at the $90 \%$ confidence level. These effects are solely found for previously treated students in cohort one, but it is important to note that only cohort one students have been in the study for two consecutive years.

\section{TABLE 4}

\section{Discussion}

We present the first experimental evidence on the effects from students attending multiple arts-related field trips. We find that treatment students received fewer behavioral infractions and reported that they enjoyed school more than their control counterparts. The significant effect on behavioral infractions is only present for treatment students a year after treatment. We believe that we are able to capture this effect due to a structural change between elementary and middle schools. Previously treated students consist of cohort one students who 
were assigned to the treatment group in fifth grade and in the second year of the study are in sixth grade where they progressed to middle school (see Table 1). Middle schools are more likely to write-up students for various behavioral infractions than are elementary schools. It is likely that treatment affects students' behavior in all grades, but that there is insufficient variation in student discipline records in elementary school for our models to detect any differences. Despite data limitations, we find evidence that arts-related field trips significantly reduce the number of infractions a student receives. These results provide causal evidence of the benefit of field trips on student behavior.

Contrary to our hypothesis, we find evidence that students in cohort one experienced test score gains from one and two years of treatment and that the effect persisted a year following treatment. We expected that treatment would have no significant impact on student test scores. We believed that three days out of school were unlikely to negatively affect test scores, but at the same time, three field trips were unlikely to provide enough math or ELA content to significantly improve scores. There are a few possible explanations for this unexpected result. First, it is possible that the treatment affects students' academic performance through school engagement. We found that treatment students experienced a significant increase in school engagement. Treatment students could have exerted greater effort in their core subjects which then affected their test scores. Second, it is possible that students learned skills or content from the field trips that assisted them on their exams. Each of The Woodruff arts partners design their programing with the Georgia state standards in mind with the goal of connecting students' experiences to classroom content. However, this seems less probably given that the field trips were only three days and unlikely to provide specific content that overlapped with a significant portion of the standardized tests. The specific mechanisms of how the field trips benefit students is unknown. 
The experimental design, while the only method to produce causal results, is, unfortunately, a black box and does not give any evidence of mediating mechanisms.

It is important to note that the test score effects are primarily for cohort one students. While there is no clear reason why the treatment affects cohort one and two students differently, there were a couple disruptions throughout the school year in the year cohort two entered the study that could affect how the cohorts responded to the treatment. First, in the fall, Hurricane Irma hit Atlanta and many schools were closed for more than a week due to loss of electricity and damage to school buildings. Second, later that same year, Atlanta also experienced severe winter storms resulting in school cancellations and rescheduling one of the three field trips. Both natural disasters resulted in multiple missed days, and while missing a few days of school is unlikely to affect test scores, missing multiple days plus the added stress of natural disasters could offset any test score increases the treatment caused. It is also possible that there are some underlying differences between cohort one and two students that we are not capturing which influences the way students respond to the treatment. However, we believe this is less likely as both cohorts are not statistically different from each other on key demographic and administrative measures. Whatever the reason for differential effects on cohorts one and two students, it is clear that missing a few days of school to attend field trips does not negatively impact student test scores. As such, the practice of reducing field trips due to accountability pressures to allow more time for instruction is not needed, and furthermore, providing students with experiences outside the classroom may even improve test scores.

\section{Conclusion}

We provide the first causal evidence of sustained academic and school engagement benefits for students from attending culturally enriching field trips. One of the most intriguing 
findings is that student test scores are not negatively affecting from missing three days of instruction and in some cases test scores substantially increase up to $16 \%$ of a standard deviation. Test score gains also remain one year after treatment. These gains are strikingly significant given that the elementary schools in our sample are generally low performing schools with very few students performing at grade level. Test score effects are particularly important when considering accountability policies. Due to increased accountability pressures to improve student test scores, many schools have opted for additional instructional time in core subjects along with extensive test preparations at the expense of other activities. However, the evidence presented here questions how effective these changes may be. While quality instruction and seat time are important for student academic progress, there are other valuable ways to increase student learning while also providing opportunities for a broader curriculum.

Many questions remain about the benefits of field trips for students; specifically, if the academic and school engagement effects we observe will persist multiple years after treatment and if additional cohorts will experience these same benefits. We hope to be able to answer these and many other questions in coming years as a third cohort is added, and as we continue to follow existing students through their middle and high school experiences.

\section{References}

Bowen, D., Greene, J., \& Kisida, B. (2014). Learning to think critically: A visual art experiment. Educational Researcher, 43(1), 37-44.

Bowen, D., \& Kisida, B. (2018). Investigating Causal Effects of Arts Education: Experimental Evidence from Houston's Arts Access Initiative. Kinder Institute for Urban Research 7(4). Accessed at https://kinder.rice.edu/research/investigating-causal-effects-artseducation-experiences-experimental-evidence-houstons-arts. 
Ellerson, N., \& McCord, R. (2009). One year later: How the economic downturn continues to impact school districts. American Association of School Administrators. Available online at http://www.aasa.org/content.aspx?id=8152.

Gadsden, V. (2008). The arts and education: Knowledge generation, pedagogy, and the discourse of learning. Review of Research in Education, 32(1), 29-61.

Gehlbach, H., Brinkworth, M., \& Wang, M. (2012). The social perspective taking process: What motivates individuals to take another's perspective? Teachers College Record, 114, 1-29.

Greene, J., Hitt, C., Kraybill, A., \& Bogulski, C. (2015). Learning from Live Theater. Education Next, Winter.

Greene, J., Kisida, B., \& Bowen, D. (2014). The educational value of field trips. Education Next, 15(1), 78-86.

Greene, J., Erickson, H., Watson, A., \& Beck, M. (2018). The play's the thing: Experimentally examining the social and cognitive effects of school field trips to live theater performances. Educational Researcher, 47(4), 246-254. Accessed at https://doi.org/10.3102/0013189X18761034

Government Accountability Office (2009). Access to arts education: Inclusion of additional questions in education's planned research would help explain why instruction time has decreased for some students. Report to Congressional Requesters. February, GAO-09286. Accessed at https://www.gao.gov/new.items/d09286.pdf

Jægar, M., \& Møllegarrd, S. (2017). Cultural capital, teacher bias, and educational success: New evidence form monozygotic twins. Social Science Research, 64, 130-144.

Keiper, S., Sandene, B., Persky, H., \& Kuang, M. (2009). The nation's report card: Arts 2008 -music and visual arts. National Assessment of Educational Progress at Grade 8. NCES 2009-488. Accessed at https://nces.ed.gov/nationsreportcard/pubs/main2008/2009488.asp

Kisida, B., Greene J., \& Bowen, D. (2014). Creating cultural consumers: The dynamics of cultural capital acquisition. Sociology of Education, 87(4), 281-295.

Lacoe, J., Painter, G., \& Williams, D. (2016). Museums as classrooms: The academic and behavioral impacts of "School in the Park." Working Paper. Sol Price School of Public Policy, University of Southern California.

Ludwig, M., Boyle, A., \& Lindsay, J. (2017). Review of evidence: Arts integration research through the lens of Every Students Succeeds Act. Washington, DC: American Institutes for Research. Accessed at http://www.air.org/resource/review-evidence-arts-integrationresearch-through-lens-every-student-succeeds-act

Randi Korn \& Associates (2018). Survey of Single-visit K-12 Art Museum Programs. Unpublished manuscript, National Art Education Association, Reston, VA. 
Rabkin, N., \& Hedberg, E. (2011). Arts education in America: What the declines mean for arts participation. National Endowment for the Arts, Research Report \#52.

Ruppert, S. (2006). Critical evidence: How the ARTS benefit student achievement. National Assembly of State Arts Agencies. Retrieved from: https://nasaaarts.org/wpcontent/uploads/2017/05/critical-evidence.pdf

Student Youth \& Travel Association (2016). Student youth and travel digest: A comprehensive survey of the student travel market. Mclean, VA. Accessed at https://syta.org/wpcontent/uploads/2017/08/SYTD-Social-Impact-8.11.pdf.

Watson A. R., Greene, J. P., Erickson, H. H., \& Beck, M. I. (2019) Altered Attitudes and Actions: Social-emotional effects of multiple Arts Field Trips. Department of Education Reform working paper 2019-04.

What Works Clearninghouse. Procedures and Standards Handbook Version 3.0. Institute of Education Sciences (IES). Accessed at https://ies.ed.gov/ncee/wwc/Docs/ referenceresources/wwc_procedures_v3_0_standards_handbook.pdf. 


\section{Tables and Figures}

Table 1: Treatment Assignment by Cohort in Year 2

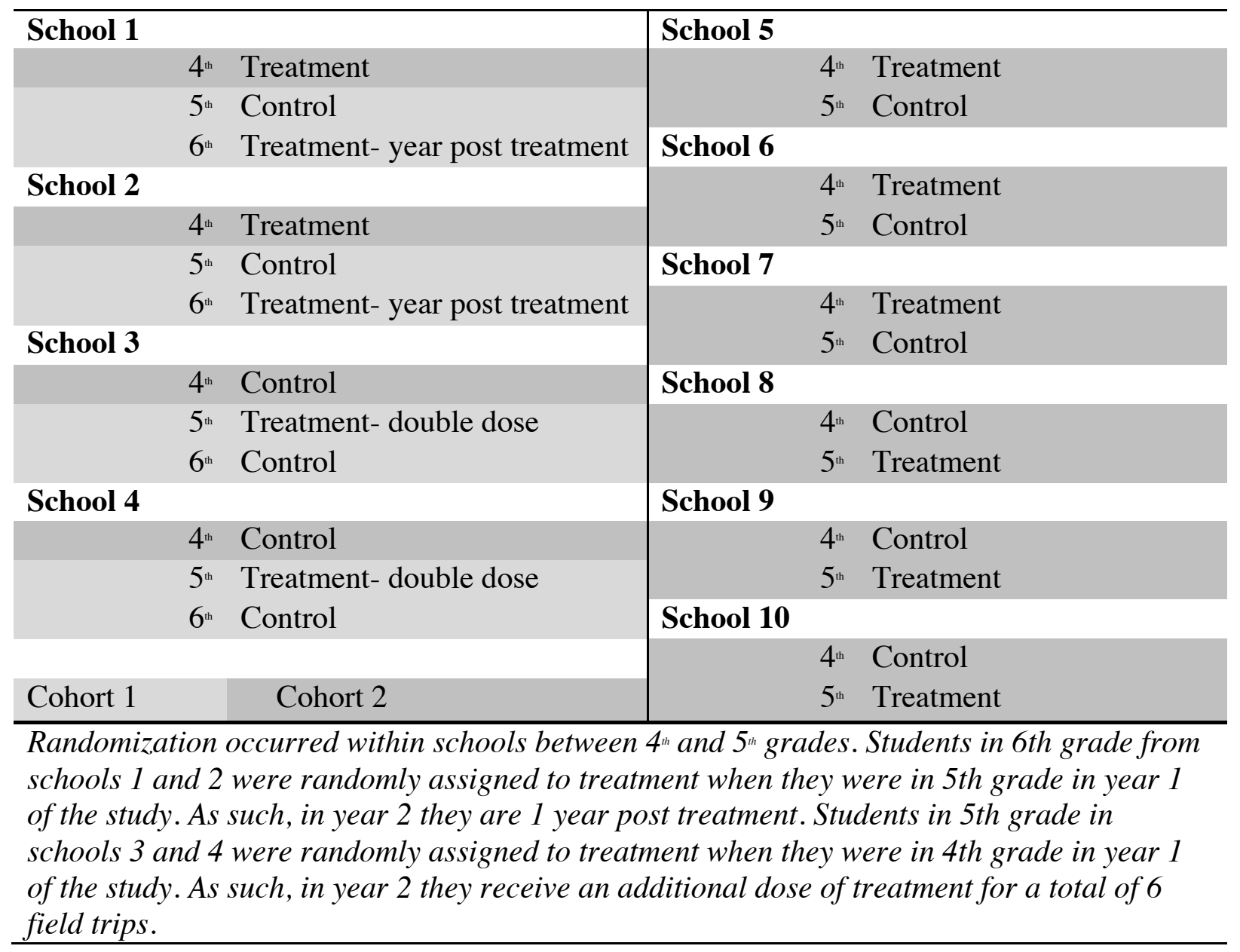


Table 2: Pre-Treatment Comparisons of Treatment and Control Groups

\begin{tabular}{lcccc}
\hline Variables & $\begin{array}{c}(\mathbf{1}) \\
\text { Control } \\
\text { (mean) }\end{array}$ & $\begin{array}{c}\mathbf{( 2 )} \\
\text { Treatment } \\
\text { (mean) }\end{array}$ & $\begin{array}{c}(\mathbf{3}) \\
\text { Difference } \\
\text { (T-C) }\end{array}$ & $\begin{array}{c}\text { Obs) } \\
\text { Observations }\end{array}$ \\
\hline $\begin{array}{l}\text { Demographics: } \\
\quad \text { Age in years }\end{array}$ & 10.48 & 10.59 & 0.11 & 1135 \\
$\quad$ Female & $51.21 \%$ & $51.14 \%$ & -0.07 & 1363 \\
$\quad$ Black or African American & $98.82 \%$ & $99.32 \%$ & 0.50 & 1018 \\
$\quad$ Students with Disabilities & $15.50 \%$ & $15.27 \%$ & -0.23 & 1228 \\
\hline Baseline Standardized Test Scores & & & & \\
$\quad$ ELA & -0.35 & -0.31 & 0.04 & 1202 \\
$\quad$ Math & -0.32 & -0.28 & 0.04 & 1201 \\
$\quad$ Combined Tests & -0.37 & -0.34 & 0.03 & 1205 \\
\hline Baseline Discipline Measures & & & & \\
$\quad$ Infractions & 0.12 & 0.12 & 0.00 & 1363 \\
$\quad$ Suspensions & 0.04 & 0.06 & 0.02 & 1363 \\
\hline Prior Year Percent Absent & $4.47 \%$ & $4.58 \%$ & 0.11 & 1228 \\
"School is Boring" & 0.04 & 0.00 & -0.04 & 1193 \\
Desire to Consume Art & -0.05 & 0.14 & $0.19 * * *$ & 1222 \\
Desire to Participate in Art & 0.03 & 0.05 & 0.02 & 1222 \\
\hline Previously attended The Woodruff & $75.10 \%$ & $80.61 \%$ & $5.51^{*}$ & 1181 \\
$\quad$ Previously attended Alliance Theatre & $32.10 \%$ & $30.84 \%$ & -1.26 & 1211 \\
$\quad$ Previously attended Atlanta Symphony & $39.74 \%$ & $47.95 \%$ & $8.21 * *$ & 1216 \\
$\quad$ Previously attended High Museum of Art & $49.03 \%$ & $52.38 \%$ & 3.35 & 1133 \\
\hline
\end{tabular}

The difference between treatment and control group students are adjusted controlling for school fixed effects. *** $p<0.01, * * p<0.05, * p<0.1$ 
Table 3: Treatment Effect on End of Grade Math and ELA Tests

\section{Combined}

1st Treatment

2nd Treatment

Previous Treatment

Pre-Composite Test Score

Female

Grade 6

Observations (N)

Number of Students
0.06

$(0.042)$

0.06

$(0.092)$

0.119 *

(0.066)

$0.857 * * *$

(0.018)

0.008

(0.035)

$-0.022$

(0.04)

1,493
Cohort 1

$0.154 * *$

(0.068)

0.166*

(0.09)

$0.128 * *$

(0.064)

$0.858 * * *$

(0.024)

0.05

$(0.051)$

0.038

(0.044)
Cohort 2

0.027

(0.057)

1,130
817

454
$0.850 * * *$

(0.021)

$-0.007$

(0.031)

889

889

Fixed effects for the ten elementary schools and student random effects are included in each model. Standard errors clustered at the teacher level are in parentheses. Observations refer to the number of observations in the panel. Number of students refers to the number of unique students in the sample $* * * p<0.01, * * p<0.05, * p<0.1$ 
Table 4: Treatment Effect on School Engagement Measures

\begin{tabular}{|c|c|c|c|c|c|c|}
\hline & \multicolumn{3}{|c|}{ Number of Infractions } & \multicolumn{3}{|c|}{ "School is Boring" } \\
\hline & Combined & Cohort 1 & Cohort 2 & Combined & Cohort 1 & Cohort 2 \\
\hline \multirow[t]{2}{*}{ 1st Treatment } & 0.049 & 0.037 & 0.072 & 0.00 & -0.06 & 0.07 \\
\hline & $(0.05)$ & $(0.076)$ & $(0.078)$ & $(0.079)$ & $(0.102)$ & $(0.109)$ \\
\hline \multirow[t]{2}{*}{ 2nd Treatment } & -0.011 & 0.024 & & 0.084 & 0.088 & \\
\hline & $(0.103)$ & $(0.109)$ & & $(0.115)$ & $(0.137)$ & \\
\hline \multirow[t]{2}{*}{ Previous Treatment } & $-0.570 * *$ & $-0.622 * * *$ & & $-0.327 *$ & $-0.425 * *$ & \\
\hline & $(0.24)$ & $(0.222)$ & & $(0.177)$ & $(0.179)$ & \\
\hline \multirow{2}{*}{$\begin{array}{l}\text { Pre-Composite Test } \\
\text { Score }\end{array}$} & $-0.159 * * *$ & $-0.171 * * *$ & $-0.111 * * *$ & 0.001 & -0.035 & 0.00 \\
\hline & $(0.036)$ & $(0.06)$ & $(0.035)$ & $(0.032)$ & $(0.04)$ & $(0.042)$ \\
\hline \multirow[t]{2}{*}{ Pre-Infraction Count } & $0.644 * * *$ & $0.780 * * *$ & $0.606^{* * *}$ & & & \\
\hline & $(0.156)$ & $(0.23)$ & $(0.152)$ & & & \\
\hline \multirow[t]{2}{*}{ Pre "School is boring" } & & & & $0.287 * * *$ & $0.234 * * *$ & $0.329 * * *$ \\
\hline & & & & $(0.036)$ & $(0.048)$ & $(0.04)$ \\
\hline \multirow[t]{2}{*}{ Female } & $-0.117 * *$ & -0.059 & $-0.161 * * *$ & $-0.110 *$ & -0.07 & $-0.176^{* *}$ \\
\hline & $(0.053)$ & $90.079)$ & $(0.056)$ & $(0.065)$ & $(0.103)$ & $(0.075)$ \\
\hline \multirow[t]{2}{*}{ Grade 6} & $0.952 * * *$ & $0.985 * * *$ & & 0.08 & 0.101 & \\
\hline & $(0.206)$ & $(0.189)$ & & $(0.136)$ & $(0.153)$ & \\
\hline Observations (N) & 1,687 & 964 & 950 & 1,176 & 657 & 690 \\
\hline Number of Students & 1,205 & 482 & 950 & 919 & 400 & 690 \\
\hline \multicolumn{7}{|c|}{$\begin{array}{l}\text { Fixed effects for the ten elementary schools and student random effects are included in each model. } \\
\text { Standard errors clustered at the teacher level are in parentheses. Observations refer to the number of } \\
\text { observations in the panel. Number of students refers to the number of unique students in the sample *** } \\
p<0.01, * * p<0.05, * p<0.1\end{array}$} \\
\hline
\end{tabular}

